REVISTA DE DERECHO UNED, NÚM. 21, 2017

\title{
LA AUTONOMÍA UNIVERSITARIA EN ECUADOR TRAS UNA DÉCADA DE LA REVOLUCIÓN CIUDADANA
}

\section{UNIVERSITY AUTONOMY IN ECUADOR AFTER A DECADE OF THE REVOLUCIÓN CIUDADANA}

\author{
Carmen Eguiguren Eguiguren \\ Alumna de la Escuela de doctorado de la UNED. \\ Docente Investigadora de la Universidad Técnica Particular de Loja, \\ Ecuador
}

Resumen: En el presente artículo se expone el debate suscitado a propósito de la autonomía universitaria en Ecuador durante una década de administración gubernativa de la denominada Revolución Ciudadana (2006-2016).

En el documento constan algunas nociones de autonomía universitaria y ciertos hechos históricos relevantes. Un breve análisis comparativo de legislaciones en países iberoamericanos, resulta en un notable colofón.

Para poner en escena el debate generado a partir de lo que fuera el proyecto de la Ley Orgánica de Educación Superior emitida en el año 2010, se toman en cuenta los pronunciamientos oficiales y los del sector universitario, representando para el efecto, por rectores universitarios y académicos.

Palabras clave: Autonomía universitaria, universidad ecuatoriana, debate alrededor de la autonomía universitaria en Ecuador, Revolución Ciudadana, educación superior en Ecuador. 
Abstract: This article discusses the debate around university autonomy during Ecuador during a decade of government administration of the so-called «Civic Revolution ${ }^{1}$ (2006-2016).

The document contains some notions of university autonomy and certain relevant historical facts. A brief comparative analysis of legislation of several Ibero-American countries results in a remarkable conclusion.

To put on the stage the debate generated from what was the draft of «Organic Law of Higher Education ${ }^{2}$ issued in 2010, official pronouncements and university members' assertions, enacted by university principals and scholars are taken into account.

Key words: University autonomy, Ecuadorian university, debate around university autonomy in Ecuador, higher education in Ecuador.

Recepción original: 07/04/2017

Aceptación original: 27/10/2017

Sumario: I. Introducción. II. Definición e historia. II.1 Definiciones. II.2 Breve recorrido histórico. III. La autonomía universitaria: Ecuador con respecto a 15 países iberoamericanos. IV. Autonomía Universitaria en Ecuador. El Debate. V. Conclusiones.

\section{INTRODUCCIÓN}

Es curioso cuán complejo puede tornarse el análisis de la autonomía universitaria hoy en día. Quizá, en el mundo contemporáneo, no es un tema que inquiete especialmente a investigadores, docentes, directivos universitarios, discentes, opinión pública o sociedad en general; pues, ¿no se libraron ya las batallas necesarias en este campo? ¿No se definió ya el ideal autonómico moderno y contemporáneo en las embrionarias universidades europeas de la baja Edad Media? ¿No fueron suficientes las luchas y la gran conmoción política resultante de la Reforma de Córdoba -Argentina- en 1918 y que se expandió con rapidez por toda América Latina?

Abordar el tema de la autonomía universitaria en Ecuador y su relación con el poder ejecutivo no resulta tarea sencilla. No -al menos- en el escenario político que provoca la administración de la Revolución Ciudadana ${ }^{3}$. Este artículo pretende exponer al lector el con-

\footnotetext{
1 Translated from «Revolución Ciudadana».

${ }^{2}$ Translated from «Ley Orgánica de Educación Superior».

${ }^{3}$ «La Revolución Ciudadana construye un proceso de cambio radical para crear el socialismo del Buen Vivir o Sumak Kawsay, una sociedad incluyente, solidaria y justa.
} 
texto de la autonomía universitaria en Ecuador tras una década de esta administración gubernativa, planteado desde la perspectiva del debate público, tanto desde el punto de vista de aquellos que han alzado sus voces de protesta con respecto al presunto ataque que habría sufrido la autonomía universitaria ecuatoriana en estos diez años ${ }^{4}$, como de aquellos que consideran que el cambio era absolutamente necesario y que no hay riesgo alguno para universidades ecuatorianas y su capacidad de auto gestionarse ${ }^{5}$.

Propongo un acercamiento a la realidad universitaria ecuatoriana a través de un breve análisis del debate público en torno a la autonomía universitaria y a las propuestas, proyectos y estrategias de la Revolución Ciudadana en cuanto a educación superior se refiere. Este documento resulta coyuntural, pues el país ahora mismo rebulle en este debate.

A pocos meses de que se cumpla el primer centenario de la Reforma de Córdoba ${ }^{6}$ y con la certeza de que la autonomía universitaria es el alma de las universidades, que las luchas por la defensa de su autonomía no han sido en vano y que la humanidad se ilumina con los reflejos de conocimiento que se originan en los centros de educación superior, doy inicio a este artículo con una breve base conceptual e histórica.

Promueve la libertad basada en la justicia, la democracia, la paz y las relaciones equitativas orientadas al bien común. Estos son los puntuales de la gran casa que ahora edificamos. La Revolución Ciudadana es la voz de los más pobres y de los desposeídos; de la gran diversidad de nacionalidades, pueblos y culturas que convivimos en este territorio. Es la voz de todos aquellos hombres y mujeres que han vivido la exclusión y la marginación, en un país que desde su nacimiento en 1830 favoreció siempre a un grupo privilegiado de una república terrateniente, aristócrata y oligárquica, que luego se convirtió en un Estado burgués débil e independiente». Recuperado en marzo de 2017 de: http://www.alianzapais.com.ec/2016/07/08/nuestras-10-revoluciones/

${ }^{4}$ No son pocos los actores del sistema de educación superior del Ecuador que se han pronunciado en el sentido de que la autonomía universitaria estaría siendo coartada, producto de una serie de disposiciones legales y reglamentarias y de la intervención del Consejo de Educación Superior, Secretaría de Educación Superior, Ciencia, Tecnología e Innovación y Consejo de Evaluación, Acreditación y Aseguramiento de la Calidad de Educación Superior del Ecuador en los procesos internos de universidades y escuelas politécnicas. Algunos pronunciamientos relevantes son expuestos en el acápite IV de este artículo.

${ }^{5}$ La mayor parte de estos pronunciamientos se han realizado desde sectores del Ejecutivo y de los organismos autónomos de la educación superior (Consejo de Educación Superior y Consejo de Evaluación, Acreditación y Aseguramiento de la Calidad de Educación Superior). Sin embargo, 4 académicos del CES han sido críticos de algunos elementos del sistema implementado. En el numeral IV de este artículo se recogen sus impresiones, dadas a conocer a través de tres manifiestos públicos puestos en consideración del país en tres momentos distintos.

${ }^{6}$ El 21 de junio de 2018 se cumplirán 100 años de este importante capítulo histórico en defensa de la autonomía universitaria. 


\section{DEFINICIÓN E HISTORIA}

\section{II.1 Definiciones}

Salvador Valencia Carmona (2003:2,28-29) aborda la concepción de autonomía desde el orden semántico, así: «autos (por sí mismo) y nomos (ley), que consiste en la facultad que una persona tiene de darse sus propias normas, sea un individuo, una comunidad o un órgano del Estado». Para este autor "ha sido en las instituciones de educación superior, y particularmente en las universidades, donde ha florecido el principio de autonomía...las universidades, para cumplir con la misión que les ha encomendado la sociedad, han pugnado siempre por realizar sus actividades en un marco de acentuada autonomía. Puede incluso afirmarse que el principio de autonomía está ligado al nacimiento mismo de la universidad...».

José Woldenberg (2008:61) señala que la autonomía «es una condición necesaria para el buen funcionamiento de la universidad moderna. Autonomía para autogobernarse, para decidir sus planes y programas de estudio, para que en su seno se ejerza la más amplia libertad de cátedra e investigación».

El Maestro Josu Landa Goyogana (2000:35 y ss.) ha establecido que la noción ordinaria de autonomía universitaria está determinada por un tipo de universidad que, a su vez, es determinado por la ecología y por la tradición cultural, propias de la formación social en la que se inscribe la universidad del caso. Continúa así, exponiendo, que el concepto de autonomía reinante en la primera Universidad de Berlín se aviene con una idea "filosófica» y profundamente humanista de la ciencia. Una idea, dice, como la que encarnaba Lichtenberg o motivaba a Goethe o a los propios hermanos Humboldt. Una idea que condensa una nueva visión del mundo, a partir de su matematización por parte de Descartes, de la introducción de la ciencia experimental por Galileo, de los descubrimientos de Newton y del reconocimiento de una base físico-química de los procesos biológicos.

Carlos Arcos Cabrera en su artículo titulado La autonomía como argumento (2010:62) grafica el análisis que hiciera Weber sobre la autonomía de las asociaciones y sobre el gráfico (página siguiente) se explica de esta manera: «A partir de las categorías propuestas por Weber es posible avanzar en la indagación sobre el campo autonomía/ heteronomía de la universidad. Atendamos, en primer lugar, a la fuente de la autonomía, o en otros términos a la fuente que regula la heteronomía. Es evidente que la concepción original de autonomía expresaba las relaciones de tensión y conflicto con el poder público 
religioso, que en los primeros momentos de la vida universitaria, en los momentos de su constitución, era un poder estatal. Las demandas por autonomía apuntaban a garantizar la llamada libertad de cátedra y la libre exposición de las ideas, que luego se volvió más compleja al incluir el nombramiento de las autoridades, es decir la autocefalia, y el cogobierno. En otro momento, la autonomía hace referencia expresa a bloquear intervenciones desde un gobierno específico, o en sentido más estructural desde el Estado, a pesar de que la universidad es un aparato del Estado ${ }^{7}$. Entre estos dos momentos conceptuales, surgen alianzas que, utilizando al Estado, reducen la influencia de la Iglesia; tal es el caso de la demanda por una educación laica. Mantener una definición de autonomía referida exclusivamente a las relaciones entre universidad y poder público estatal es a todas luces un arcaísmo, que sobrevive de las primeras luchas por la autonomía».

\section{Tabla 1. El campo de significados de la autonomía/heteronomía de las asociaciones, según Max Weber}

\begin{tabular}{|c|c|c|c|}
\hline & & \multicolumn{2}{|c|}{ El origen del orden } \\
\hline \multicolumn{2}{|c|}{ Campos específicos } & $\begin{array}{l}\text { Autonomía } \\
\text { El orden de la asociación } \\
\text { está otorgado -impuesto- } \\
\text { por sus propios miembros } \\
\text { y en virtud de la cualidad } \\
\text { de tales. }\end{array}$ & $\begin{array}{l}\text { Heteronomía } \\
\text { El orden de la asociación } \\
\text { está otorgado -impuesto- } \\
\text { por alguien fuera de la } \\
\text { misma y exterior a ella. }\end{array}$ \\
\hline \multirow[b]{2}{*}{$\begin{array}{l}\text { Nombramiento } \\
\text { de la autoridad }\end{array}$} & $\begin{array}{l}\text { Autocefalia } \\
\text { El dirigente de la asocia- } \\
\text { ción es nombrado por el } \\
\text { orden de la asociación. }\end{array}$ & I. Autonomía + Autocefalia & $\begin{array}{l}\text { II. Heteronomía + } \\
\text { Autocefalia }\end{array}$ \\
\hline & $\begin{array}{l}\text { Heterocefalia } \\
\text { El dirigente de la asocia- } \\
\text { ción es nombrado por } \\
\text { alguien externo a ella } \\
\text { (cualquiera que sea la for- } \\
\text { ma del nombramiento) }\end{array}$ & $\begin{array}{l}\text { III. Autonomía + } \\
\text { Heterocefalia }\end{array}$ & $\begin{array}{l}\text { IV. Heteronomía + } \\
\text { Heterocefalia }\end{array}$ \\
\hline
\end{tabular}

Fuente: Arcos, Carlos (que fuera Rector del Instituto de Altos Estudios Nacionales del Ecuador). Fuente citada por el autor del gráfico: Weber, 1996: 40. (2010:62).

${ }^{7}$ La tesis de que las universidades son un apartado del Estado ha sido ampliamente desarrollada por el Eco. René Ramírez (presidente del Consejo de Educación Superior hasta septiembre de 2016 y Secretario de Educación Superior), en el sentido de una educación superior como bien público: «Uno de los ejes que atraviesa el cambio de mirada respecto al sistema de educación superior en general y de la universidad en particular consiste en redefinirla como un bien público. Partiendo de esta idea, el Ecuador ha iniciado un proceso de transformación radical, que marca distancias inclusive con países de larga tradición reformista-progresista (como Argentina y México)...» (Ramírez, 2013:15). 
La Constitución de la República del Ecuador expedida en el año $2008^{8}$, señala en su artículo 355 -en relación a la autonomía universitaria- que «El Estado reconocerá a las universidades y escuelas politécnicas autonomía académica, administrativa, financiera y orgánica, acorde con los objetivos del régimen de desarrollo y los principios establecidos en la Constitución. Se reconoce a las universidades y escuelas politécnicas el derecho a la autonomía, ejercida y comprendida de manera solidaria y responsable. Dicha autonomía garantiza el ejercicio de la libertad académica y el derecho a la búsqueda de la verdad, sin restricciones; el gobierno y gestión de sí mismas, en consonancia con los principios de alternancia, transparencia y los derechos políticos; y la producción de ciencia, tecnología, cultura y arte. La autonomía no exime a las instituciones del sistema de ser fiscalizadas, de la responsabilidad social, rendición de cuentas y participación en la planificación nacional».

El artículo 18 de la Ley Orgánica de Educación Superior de 2010², señala a la autonomía como la capacidad de las universidades de:

a) La independencia para que los profesores e investigadores de las universidades y escuelas politécnicas ejerzan la libertad de cátedra e investigación;

b) La libertad de expedir sus estatutos en el marco de las disposiciones de la presente Ley;

c) La libertad en la elaboración de sus planes y programas de estudio en el marco de las disposiciones de la presente Ley;

${ }^{8}$ Esta Carta Magna fue producto de una Asamblea Constituyente convocada para su redacción. El preámbulo de la Constitución del 2008 menciona la decisión de construir «una nueva forma de convivencia ciudadana, en diversidad y armonía con la naturaleza, para alcanzar el buen vivir, el sumak kawsay; una sociedad que respeta, en todas sus dimensiones, la dignidad de las personas y las colectividades; un país democrático, comprometido con la integración latinoamericana-sueño de Bolívar y Alfaro., la paz y la solidaridad con todos los pueblos de la tierra...»

${ }^{9}$ Este Cuerpo Normativo, expedido el 12 de octubre de 2010, tiene como base la Constitución de la República del Ecuador del año 2008. Uno de los considerandos de la Ley Orgánica de Educación Superior establece la necesidad de dictar una nueva ley de educación superior que "contribuya a la transformación de la sociedad, a su estructura social, productiva y ambiental, formando profesionales y académicos con capacidades y conocimiento que respondan a las necesidades del desarrollo nacional y a la construcción de ciudadanía» Su objeto es el de definir los principios del sistema de educación superior, garantizar el derecho a una educación superior de calidad que propenda a la excelencia, el acceso universal al sistema, la permanencia en el mismo, la movilidad y el egreso sin discriminación alguna. 
d) La libertad para nombrar a sus autoridades, profesores o profesoras, investigadores o investigadoras, las y los servidores y las y los trabajadores, atendiendo a la alternancia y equidad de género, de conformidad con la Ley;

e) La libertad para gestionar sus procesos internos;

f) La libertad para elaborar, aprobar y ejecutar el presupuesto institucional. Para el efecto, en el caso de instituciones públicas, se observarán los parámetros establecidos por la normativa del sector público;

g) La libertad para adquirir y administrar su patrimonio en la forma prevista por la Ley;

h) La libertad para administrar los recursos acorde con los objetivos del régimen de desarrollo, sin perjuicio de la fiscalización a la institución por un órgano contralor interno o externo, según lo establezca la Ley, e

i) La capacidad para determinar sus formas y órganos de gobierno, en consonancia con los principios de alternancia, equidad de género, transparencia y derechos políticos señalados por la Constitución de la República, e integrar tales órganos en representación de la comunidad universitaria, de acuerdo a esta Ley y los estatutos de cada institución.

Entonces, tanto en la doctrina como en la norma, se evidencia que la autonomía universitaria implica autogobierno, decisión de planes y programas académicos y libertad de cátedra e investigación; y, una amplia libertad académica, administrativa y financiera, libertad ésta que permite alcanzar la consecución de los fines de las universidades.

\section{II.2 Breve recorrido histórico}

Nada más pensar en autonomía universitaria y en libertad de cátedra y aparece en nuestra memoria la imagen de la universidad histórica y, específicamente, las universidades en Bolonia y París quienes nacieron en contextos históricos diferentes a las corporaciones educativas del siglo XII ${ }^{10}$.

${ }^{10}$ Corporaciones educativas del siglo XII que se generan a partir de la docencia como actividad específica entre aprendices y maestros y como un modo de vida. Ordorika (citado a continuación-p. 20) nos dice en su obra que los miembros de la comunidad académica se esforzaron por crear sus propios acuerdos corporativos de cara a la Iglesia, las autoridades seculares y el resto de la sociedad; volviéndose, gra- 
Es que autonomía universitaria necesariamente se relaciona con la historia de las universidades ${ }^{11}$, pues es un nexo causal inminente. La historia de la universidad en el mundo, como institución en la que existen ya los conceptos de docencia y aprendizaje formal.

IImanol Ordoika (2006:21 y ss.) nos refiere a las primeras universidades de Bolonia y París como independientes de la corriente universitaria del siglo XII. A fines del siglo XII, dice, la Universidad de Bolonia surgió del impulso de la comunidad estudiantil, sacando provecho de la rivalidad entre el papa y el emperador y consiguiendo importantes privilegios y una jurisdicción amplia. La Universidad de París -afirma Ordorika-, tenía una estrecha relación con la Iglesia, creándose a finales del siglo XII también, a partir de las escuelas catedralicias de Notredame. Importante recalcar que estas dos universidades alcanzaron un alto grado de autonomía y extensión de privilegios y jurisdicciones, gracias a la ausencia de una fuente única y centralizada de poder en las sociedades medievales de finales del siglo XII.

Valencia Carmona (2003:29 y ss.) llama la atención al lector en su obra, sobre el hecho inusitado de que una comunidad académica -la Universidad de Bolonia- lograra una considerable autonomía en el estudio y enseñanza del derecho, hasta el punto, dice, que se convirtió en un centro internacional de mucho prestigio para los estudios jurídicos. Para este autor es relevante el hecho de que la Universidad de Bolonia alcanzara gran reconocimiento social y que el propio emperador Federico I Hohenstaufen haya emitido en 1158 la Authentica $H_{a b i t a}{ }^{12}$, que concedió la protección imperial a maestros y estudiantes de esta universidad.

cias a estos privilegios, muy poderosas, sin ser completamente autónomas respecto a la Iglesia o al Estado, como resultado de ello no estuvieron exentas de intervenciones externas.

11 Universitates, término que remitía originalmente a las comunidades, a los gremios o a las corporaciones que gozaban del reconocimiento público.

${ }^{12} \mathrm{Si}$ bien Valencia refiere la Authentica Habita en su obra como un documento emitido en 1158 por Federico I Hohenstaufen,, Nichole SLACK, en su artículo titulado "Authentica Habita and The Protection of Medieval Roma Scholars», publicado en la dirección electrónica http://www.humanstudy.org/history/2012-04-slack-n.html (recuperado en agosto de 2016), señala como el emisor de este documento al emperador Federico Barbarossa. En todo caso, coinciden los dos autores en que el documento trata sobre la protección imperial a los estudiantes y maestros en tránsito y dependencia directa del obispo diocesano o de su representante, el «magister scholarium», en una época en que las carreteras eran inseguras y las ciudades eran peligrosas. A decir de Slack, el emperador consideró la necesidad de proteger de estos peligros a los académicos y sintió compasión de ellos: «who for love of learning choose exile and poverty, and divest themselves of their patrimony while exposing themselves to every peril and suffering what must be most grievous to endure: bodily injuries 
Es en el siglo XVI que, bajo el amparo de bulas papales y decretos reales, se fundaron las primeras universidades en el continente americano: Santo Domingo (1538), Perú y México (1551). Fue alto el grado de autonomía que tuvieron estas universidades coloniales mientras estuvieron regidas por órdenes religiosas.

Es herencia autonómica universitaria, de primerísimo orden para América Latina, lo ocurrido a raíz de la llamada Reforma de Córdova o Manifiesto de Córdoba (1918) en relación a la autonomía universitaria y su movimiento. Emblemática es la defensa de la autonomía en las universidades a partir de esa fecha. Latinoamérica dice no a la violación por la vía de la irrupción de las fuerzas públicas en las actividades universitarias mediante regulaciones estatales de diferente tipo y calidad.

¿Qué es pues la Reforma de Córdoba? Significa, sin más, el manifiesto que hacen hombres libres -de librepensamiento- a los hombres libres de Sud América. Es un rompimiento, a decir del mismo Manifiesto, de la cadena que ataba a la universidad con la dominación monárquica y monástica.

La carta que suscriben estos librepensadores y auténticos independistas, habla sin tapujos sobre una universidad que hasta esa fecha había sido refugio secular de mediocres, la renta de los ignorantes, la hospitalización segura de los inválidos y el lugar en donde todas las formas de tiranizar y de insensibilizar hallaron la cátedra que las dictara.

El Manifiesto continúa acotando que las universidades han llegado a ser así «fiel reflejo de estas sociedades decadentes que se empeñan en ofrecer el triste espectáculo de una inmovilidad senil. Por eso es que la ciencia frente a estas casas mudas y cerradas, pasa silencio-

without cause from the vilest of men»; por tanto el decreto fue un gran avance en la protección de estos académicos en todo el imperio romano.

Qué actual resulta ahora, a la luz de este siglo, la preocupación del emperador Federico I, en un país como Ecuador y en muchos países de Latinoamérica, cuando la delincuencia cobra vidas valiosas día con día. La reflexión que hace el emperador es terrible y descarnadamente actual. En este tercer mundo, los estudiantes emigran en busca de conocimiento y "por amor al conocimiento escogen el exilio y la pobreza, abandonando su patrimonio", van a las grandes ciudades donde se concentra ese conocimiento; también allí, sin embargo, se concentran las acciones delincuenciales. Muchos académicos (maestros y estudiantes) se ven expuestos a ella; obviamente, no más que cualquier ciudadano común, no hay direccionalidad de esta delincuencia hacia la academia, sin embargo, quien está exiliado por amor al conocimiento, lejos de su terruño y sufriendo privaciones, sufre con mayor impacto si es sujeto de actos delincuenciales, estando alejado de lo familiar. Quizá la razón del emperador Federico en 1158 , debería llamar a la reflexión a los gobernantes del siglo XXI. 
sa o entra mutilada y grotesca al servicio burocrático». Define a su régimen académico como anacrónico, fundado sobre una especie de derecho divino -el del profesorado universitario-, que se crea a sí mismo. Empuña la espada de la lucha cuando nombra a la Federación Universitaria de Córdoba como la que se alza para combatir contra ese régimen. El Manifiesto es un avance pedagógico revolucionario para su tiempo, se atreve a verter ideas de tal magnitud como: "si no existe una vinculación espiritual entre el que enseña y el que aprende, toda enseñanza es hostil y por consiguiente infecunda. Toda educación es una larga obra de amor a los que aprenden»

Se ocupa también de la normativa tiránica cuando señala con propiedad que fundar la garantía de una paz fecunda en el artículo conminatorio de un reglamento o de un estatuto es amparar un régimen de cuartel, pero no una labor de ciencia.

En Ecuador, en el año 1918, los estudiantes de la Universidad Central organizaron la Federación Universitaria que levantó la bandera de las reivindicaciones universitarias y populares. Manuel Agustín Aguirre $^{13}(1973: 53,112)$, señala que la Legislatura de 1918 concedió un delegado estudiantil por cada Facultad ante la Junta General de Profesores; y, el Congreso de 1922, por presión estudiantil, amplía esta representación a la Junta Administrativa y Junta de la Facultad, elevando el número de delegados estudiantiles a la tercera parte del número de profesores. Y, en cuanto a las cruentas luchas por la autonomía universitaria de esos años: «El día 28 de mayo de 1969, un día antes de mi posesión de Rector de la Universidad Central, 15 a 20 estudiantes fueron asesinados por la fuerza pública en la Universidad de Guayaquil, debido a su lucha por la supresión de los exámenes de ingreso, en un afán de democratizar la Universidad»

Aguirre narra en su obra que es ese momento en el cual se levanta la Segunda Reforma Universitaria, y manifiesta que la denominaron así pues se consideró que la Reforma Universitaria y democrática de Córdova constituía el primer esfuerzo que realizó la Universidad latinoamericana por encontrarse a sí misma. Señala que esta Reforma

${ }^{13}$ Connotado profesional ecuatoriano del Derecho, fue fundador del Partido Socialista Revolucionario del Ecuador, fue destacado personaje del socialismo ecuatoriano. Diputado de la Asamblea Nacional de 1945 y Rector de la Universidad Central del Ecuador en el año 1969, fue despojado de este cargo por la dictadura del Dr. José María Velasco Ibarra en 1970. Fue autor de obras como la Realidad Ecuatoriana, la Revolución Burguesa o Revolución Proletaria para América Latina, el Imperialismo y Militarismo en América Latina, las Dictaduras Militares en el Cono Sur y la Masacre del 15 de noviembre de 1922 y sus Enseñanzas. Recuperado en marzo de 2017 de: https://www.ecured.cu/Manuel_Agust\%C3\%ADn_Aguirre 
estaba especialmente empeñada en conseguir para las universidades rentas propias (no como empresa financiada al estilo norteamericano) por medio de la creación de impuestos permanentes a ser recaudados por el Banco Central, para una posterior distribución entre las universidades ${ }^{14}$.

\section{LA AUTONOMÍA UNIVERSITARIA: ECUADOR CON RESPECTO A 15 PAÍSES IBEROAMERICANOS}

El análisis de las legislaciones que regulan la educación superior en 15 países iberoamericanos ${ }^{15}$ (Argentina, Bolivia, Brasil, Chile, Colombia, Costa Rica, España, México, Panamá, Paraguay, Perú, Puerto Rico, República Dominicana, Uruguay y Venezuela) nos esboza una autonomía universitaria que, más o menos, contempla tópicos tales como:

- Autonomía académica, de investigación y financiera,

— Libertad de cátedra,

- Inviolabilidad de recintos universitarios,

- Capacidad de producir la propia normativa interna (Estatutos),

- Capacidad para elegir su propio gobierno,

- Cogobierno,

- Capacidad para regular su oferta de carreras y programas: crearlos, mantenerlos o suprimirlos,

${ }^{14}$ Ecuador se encuentra dolarizado desde enero del año 2000, con un dólar equivalente a 25.000 sucres (el sucre era la moneda de curso legal en Ecuador hasta ese año). Quizá con nostalgia, transcribo la propuesta de los catedráticos al entonces Congreso Nacional: el 11\% adicional a la renta anual de las personas que tuvieran un ingreso de más de 4.200 sucres (para esos años 1 dólar equivalía a, más o menos, 25 sucres) mensuales, el mismo que debía incrementarse por las condiciones de su propio dinamismo; 3 sucres por litro de aguardiente; y una participación equivalente a 24 millones de sucres, anuales, de la suma que el Gobierno nacional pagaba al Banco Central en esa época por concepto de intereses correspondientes a la deuda pública. La propuesta, dice Manuel Agustín Aguirre, fue aceptada y permitió que las universidades continuaran desenvolviendo sus actividades.

${ }^{15} \mathrm{El}$ análisis comparativo con estos 15 países pasa por el hecho de que presentan circunstancias sociales similares en cuanto a sus sistemas de educación superior. Al menos en cuanto a normativa que regula este sector, se puede apreciar similitudes que sirven como base para un análisis comparado de legislaciones. El caso de España resulta distinto por ser este país parte de la Unión Europea, sin embargo he tomado su legislación como base para el estudio comparativo por considerar que su legislación contiene ciertos factores análogos al caso ecuatoriano, sobre todo en cuanto se refiere a declaratoria de autonomía universitaria y su alcance. 
- Capacidad para establecer los planes de estudio de carreras y programas,

- Capacidad para otorgar títulos, grados, diplomas, etc.,

- Capacidad para regular el acceso, permanencia y promoción de personal docente y no docente; así como, la regulación de acceso, permanencia y titulación de estudiantes,

- Capacidad para administrar su patrimonio.

La normativa estudiada también controla, evalúa calidad, acredita, tiene capacidad de intervención, sanciona, estableciendo:

- Normas y procedimientos de creación de entidades de educación superior, sedes y extensiones,

- Organismos rectores, contralores, vigilantes y supervigilantes de organismos de la educación superior,

- Organismos que evalúan la calidad académica de las instituciones de educación superior, de sus carreras y programas; y, que los acredita,

- Las condiciones de intervención universitaria y sus procedimientos,

- Las sanciones a imponer a entes de educación superior ante faltas a la normativa.

De una u otra forma, se prevé la autonomía universitaria al tenor de una normativa que busca, en algunos casos, el equilibrio entre aparataje estatal y su poder y una autonomía universitaria responsable; y, en otros, control de la actividad de la educación superior, tomando ésta siempre como punto referencial de la producción del conocimiento; y, como tal, del libre pensamiento.

Ecuador, en el año 2010, exhibe al mundo una nueva normativa de educación superior como resultado de un muy publicitado consenso social $^{16}$ y que encuadra, limita y enmarca lo que será la educación superior a partir de esa fecha. La Ley Orgánica de Educación Superior contempla la autonomía universitaria en términos similares a los analizados en la normativa analizado de los otros 15 países. La Ley

${ }^{16}$ En su momento la Secretaría Nacional de Planificación y Desarrollo -SENPLADES- y la Asamblea Nacional del Ecuador realizaron talleres y foros a nivel nacional, para realizar socializaciones de lo que sería la Ley Orgánica de Educación Superior. El debate apuntó a que estos foros y talleres solamente fueron informativos y que no se generó el espacio necesario para que los actores puedan expresar su criterio con respecto al proyecto. 
Orgánica de Educación Superior de 2010 contempla los presupuestos básicos sobre autonomía universitaria, aunque tópicos como la facultad de diseñar y ofertar carreras y programas académicos quedan en entredicho ${ }^{17}$. Sin embargo de ello, cuando se implementa la norma reglamentaria e instruccional emitida por el Consejo de Educación Superior -CES-, el Consejo de Evaluación, Acreditación y Aseguramiento de la Calidad de Educación Superior -CEAACES- y la Secretaría de Educación Superior, Ciencia, Tecnología e Innovación -SENESCYT, las estructuras académico administrativas de las universidades sufren un choque, que pudiera ser un reto o pudiera ser una amenaza -según se vea- y que se recoge en las próximas líneas en forma del debate social a propósito de los cambios implementados en educación superior desde la ideología de la Revolución Ciudadana.

\section{AUTONOMÍA UNIVERSITARIA EN ECUADOR. EL DEBATE}

"¿Y qué hacen las comunidades científica, académica artística?» se pregunta Mayor Zaragoza (2011:12). Responde, con una inquietante reflexión "Siguen observando. En general, son espectadores distraídos que no reflexionan suficientemente sobre los grandes problemas ni actúan en consecuencia. No se aperciben todavía del enorme poder ciudadano».

Es a partir de esta reflexión que me propongo abordar el tema del debate en el Ecuador con respecto a la autonomía universitaria durante y tras la década de la Revolución Ciudadana.

En el Enlace Ciudadano No. 51718, Rafael Correa en su calidad de Presidente Constitucional de la República del Ecuador ha dicho: «an-

${ }^{17} \mathrm{La}$ autonomía debe permitir a las universidades la posibilidad de diseñar y ofertar carreras y programas sin necesidad de una aprobación previa por parte de organismos rectores de la educación superior. Posteriores procesos de evaluación y acreditación podrían resultar suficientes para garantizar la calidad de la oferta. En Ecuador, por mandato de Ley, las universidades iniciaron un proceso de rediseño de carreras, mismo que se realiza ante el Consejo de Educación Superior -CES-. En tal virtud, más de cincuenta universidades presentan, casi al mismo tiempo, toda su oferta académica para aprobación del CES. A marzo de 2017 y luego de más de dos años de procesos administrativos, muy pocos rediseños están aprobados, los demás se encuentran en espera.

${ }^{18}$ Llevado a cabo el día 25 de marzo de 2017 desde el cantón Ruminañui de la provincia de Pichincha. El Enlace Ciudadano, conocido también como «sabatina», es un espacio de radio y televisión que se emite los días sábados y por el lapso de 3 horas y que generalmente se lleva a cabo por el mismo Presidente de la República del Ecuador. Mantiene un formato de información al pueblo ecuatoriano sobre las actividades que se realizan desde la Presidencia y busca mantener contacto con la pobla- 
tes... las universidades públicas se pagaban... ¿Qué equilibrio es ése? La realidad es que había caótico acceso, hoy con orgullo les digo: somos el país que más invierte en educación superior en América Latina y de los que más invierte en el mundo. Ésa es la realidad... ése es el debate. ¿Qué queremos nuevamente? ¿Una educación como mercancía? ¿Solo el que pueda pagársela puede acceder a ella? o ¿la educación como derecho? en base al mérito, fundamento para la igualdad de oportunidades, para la igualdad social, incluso para la verdadera democracia que es igualdad de oportunidades...»

Estas palabras del Eco. Correa han sido repetidas en innumerables intervenciones, en similar sentido, por los funcionarios de entes rectores y planificadores de la educación Superior en el país. El Eco. René Ramírez ${ }^{19}$, por ejemplo, cuenta con numerosas publicaciones en las cuales da a conocer el modelo de educación superior a partir de la Revolución Ciudadana y las conjeturadas bondades del mismo.

Es que tras conocerse la intención de reformar la Ley de Educación Superior, hacia el año 2009, en Ecuador se generó un debate social con respecto a la autonomía universitaria y la necesidad de que ésta se asiente en la reforma de esta Ley.

Como producto de los anuncios de las reformas a la Ley Orgánica de Educación Superior, el 30 de enero de 2009 -entre otras muchas marchas en el país- estudiantes lojanos salen a las calles para «defender la autonomía universitaria y la entrega oportuna de recursos» ${ }^{20}$. Portando banderas rojas y verdes y carteles, pedían el respeto por la autonomía de la Universidad Nacional de Loja (una de las más antiguas del Ecuador), así como el libre ingreso de estudiantes a la Universidad.

El dirigente estudiantil César Benavides también toma la palabra en esta marcha para enfatizar que «apoyaron la aprobación de la Constitución, pero que hoy se sienten traicionados, porque se irrespeta la autonomía universitaria, la gratuidad de la educación y el libre ingreso» y «... el principio de la autonomía universitaria se encuentra seriamente amenazado en las instituciones de educación superior del país...en definitiva el Ministerio de Finanzas está contraviniendo el artículo 355 de la Constitución que dice: el Estado garantizará la autonomía académi-

ción. Estos enlaces han sido fuertemente criticados por los costos que representan para el Estado y porque en ellos se realiza una suerte de dura crítica a sectores como la prensa, la empresa privada y la oposición.

${ }^{19}$ Ex Secretario Nacional de Planificación y Desarrollo, ex Presidente del Consejo Nacional de Educación Superior, Secretario Nacional de Educación Superior. Sus pronunciamientos están publicitados en su blog: www.reneramirez.ec.

${ }^{20}$ Recuperado en julio de 2016 de: http://lahora.com.ec/index.php/noticias/ show/832627/-1/Universidades_piden_respeto_.html\#. V56vtfnhDZ4 
ca, administrativa, financiera. Por lo tanto al disminuirnos el presupuesto (...) implica que se afecte la calidad de la educación».

El debate está en ebullición. El 14 de julio de 2009 vuelven a salir a las calles del país los estudiantes de sistema de educación superior del país, dentro del debate político y académico de la reforma a la LOES. Uno de los puntos más controvertidos de este debate se refiere a la capacidad de universidades y escuelas politécnicas de autogobernarse. Se presume que la autonomía está en riesgo, que no se toman en cuenta las aspiraciones de las instituciones de educación superior y que con ello se vulnera su autonomía, sometiendo a estas instituciones a las decisiones de Secretaría Nacional de Planificación y Desarrollo-SENPLADES-, que es la decisión del Gobierno presidido por Rafael Correa y la Revolución Ciudadana.

El entonces Secretario Nacional de Planificación y Desarrollo, Econ. René Ramírez (más tarde y hasta hoy Secretario Nacional de Educación Superior -con rango de Ministro- y Presidente del Consejo de Educación Superior -CES- hasta septiembre de 2016), también opinaba que no debía ser la reforma a la LOES un tema que deba preocupar al sector universitario, porque: «...el proyecto no rompe para nada la autonomía de las universidades del Ecuador. Se habla de libertad de cátedra, autonomía financiera, de contratación de personal y otras cosas...» ${ }^{21}$.

En el año 2010 continúa la polémica sobre la reforma de la Ley. Es así que la revista de análisis político La Tendencia, trae consigo el artículo Autonomía Universitaria y sociedad de mercado de autoría de la Subsecretaria de SENPLADES, Ana María Larrea. En este documento Larrea menciona:

«El proyecto de Ley Orgánica de Educación Superior presentado por el Ejecutivo a la Asamblea Nacional ha colocado el tema de la autonomía universitaria en el centro del debate público. La autonomía universitaria ha sido, sin duda, una de las más importantes reivindicaciones históricas de la comunidad académica que data desde el nacimiento de la Universidad como espacio del conocimiento y del saber. No es por tanto, un tema nuevo. Sin embargo, como todo concepto, sus implicaciones son un producto histórico, fruto de las condiciones de la vida social en las que emerge y se desarrolla. En las condiciones históricas de la sociedad ecuatoriana actual, cabe preguntarse, ¿qué autonomía requiere la Universidad ecuatoriana para cumplir adecuadamente su rol en la construcción del Buen Vivir de los ecuatorianos y ecuatorianas?»

${ }^{21}$ Recuperado en julio de 2016 de: http://ahora.com.ec/index.php/noticias/ show/832627/1/Universidades_piden_respeto_.html\#. V56vtfnhDZ4 
Luego de hacer una breve síntesis histórica sobre autonomía universitaria y su desarrollo, cita a Kant (que sostiene que la autonomía universitaria es una obligación ética del gobernante y que para poder alcanzarla se requiere un pacto entre comunidad académica y comunidad civil); y, manifiesta que a su entender en el Ecuador el Estado no ha cumplido su rol frente a la Educación Superior. Esgrime sus razones, que no son distintas a las que el Gobierno había manifestado antes, cuando dice que el Estado ecuatoriano habría dejado abandonada a su suerte a la educación superior, permitiendo con ello una merma significativa de calidad y la proliferación de universidades sin condiciones para transmitir conocimiento.

Retoma el debate Manuel Corrales Pascual (2012), Rector de la Pontificia Universidad Católica del Ecuador y para ello recuerda que «autonomía universitaria es la potestad que tiene la universidad para regirse mediante normas y órganos de gobierno propios». Se pregunta sobre los fundamentos de ésta y señala:

«Les diré con toda claridad y franqueza que soy de aquellos que fundamentan la autonomía universitaria en la mismísima dignidad de la persona humana. Porque en la dignidad humana radican la libertad y los derechos de la persona en su dimensión individual y social. Yo añadiría que la autonomía es la condición de posibilidad para que la Universidad pueda realizar su triple misión de buscar la verdad, trasmitirla y ponerla al servicio de la comunidad. El "poder saber" -que es el poder propio de la Universidad-no puede ejercitarse si la universidad no se da a sí misma el gobierno apropiado y las normas que aseguren el cabal cumplimiento de su triple misión.»

La Universidad de Cuenca también se pronuncia con respecto a la Ley Orgánica de Educación Superior expedida en octubre de 2010. Lo recoge el Diario El Mercurio de la ciudad de Cuenca el 19 de octubre de $2012^{22}$. Se hace hincapié en que es una universidad que cumple 145 años y que el aniversario se encuentra marcado por nuevas reglamentaciones, entre ellas, la Ley Orgánica de Educación Superior. El Rector de esta Universidad en esa fecha, Fabián Carrasco, expresa que la emisión de la Ley propone obligaciones que no se pueden cumplir sin asignaciones y en los plazos que ésta dispone. Como un ejemplo cita la obligación de que en un plazo de cinco años al menos el $70 \%$ de los maestros tengan título de PhD. Con un total de 1000 docentes en esa Institución, y cuando sólo 38\% cumplía con este requisito, Carrasco explicaba que en ese espacio de tiempo no es posible preparar a los catedráticos para que obtengan ese grado académico,

${ }^{22}$ Recuperado en julio de 2016 de: https://www.elmercurio.com.ec/353547-universidad-debate-por-su-autonomia/\#. V5WD8PnhDZ4 
pues el sistema educativo de ese momento no tenía capacidad para la formación de profesores.

En el debate interviene el ex presidente del CONEA -Consejo Nacional de Evaluación y Acreditación de la Educación Superior del Ecuador-, Arturo Villavicencio (2013), y manifiesta que el informe que el CEAACES elevó como producto de la evaluación de las Universidades y en el cual categorizó a las mismas «se trata de un informe neobarroco de categorización lleno de cuadros, tablas, coloridos». Villavicencio sale a la palestra pública con críticas durísimas al sistema de categorización de universidades y escuelas politécnicas, manifestando inclusive que el proceso se usa «como arma de control y vigilancia para universidades ecuatorianas» y que CEAACES prácticamente no tiene autonomía pues actúa como dependencia del Gobierno.

«Han transcurrido 4 años desde que se realizó el último informe, en el tiempo transcurrido se han aplicado algunas reformas que han cambiado el sistema de educación superior, entonces, era el momento de hacer un análisis, una reflexión de qué se ha logrado, qué es lo que queda por hacer.»

Es el mismo Arturo Villavicencio que vuelve al debate con su artículo ¿Hacia dónde va el proyecto universitario de la revolución ciudadana? (2013). En el documento hace notar que atendiendo al sentido de urgencia y premura, que el Gobierno y las instituciones que regulan el sistema de educación superior, tienen por reconfigurar el sistema, se ignoran los ritmos de procesos orgánicos y de evolución, procesos que no pueden ser impuestos y controlados desde arriba:

«Como estos temas son nuevos en las esferas de planificación y decisión gubernamentales, existe una dosis de confusión sobre la aplicación y efectividad de herramientas e instrumentos de política; ofuscación que está haciendo perder las perspectivas históricas, el sentido de orientación y que pone en riesgo una oportunidad histórica de sentar bases sólidas par aun sistema universitario de calidad y sobre todo, de compromiso y responsabilidad con el contexto social al cual se debe.»

Villavicencio manifiesta que existe una peligrosa tendencia a adoptar esquemas educativos, modelos universitarios, criterios de calidad, que son exitosos en otras realidades, sin tomarse el tiempo y el cuidado para establecer si éstos se adaptarían a nuestra propia realidad. No desconoce que existen aspectos positivos de otras experiencias, pero se hace necesario, para su incorporación, no perder de vista nuestra propia identidad y naturaleza y sin atender a modelos hegemónicos y 
pautas foráneas dominantes. Habla de una suerte de «colonialismo académico» que niega la experiencia y la historia de la universidad ecuatoriana y que ignora el papel fundamental que ésta ha jugado en el repositorio de la cultura nacional.

No son ajenos al debate más de 100 académicos ecuatorianos de las distintas universidades y escuelas politécnicas del país, que en el 2014 publican un Manifiesto ${ }^{23}$ que recoge sus inquietudes alrededor del modelo de evaluación de universidades ecuatorianas por parte del CEAACES, a partir de la expedición de la Ley Orgánica de Educación Superior. No discrepan, manifiestan, de la evaluación universitaria como herramienta para garantizar la mejora continua del sistema de educación superior; les preocupa, dicen, el modelo de universidad «ideal» que a su entender subyace en el proceso de evaluación de CEAACES. Un modelo disciplinario y vertical que no toma en cuenta las evaluaciones docentes realizadas por estudiantes en cada una de las universidades, en el cual las universidades no fueron informadas oportunamente sobre las herramientas de análisis o sobre las ponderaciones de los indicadores, orientado a la creación de un «ranking» que categoriza a las universidades en un orden jerárquico y según moldes comerciales, en el que el CEAACES no dispone de un documento que discuta, exponga y defina qué entiende por calidad, para el que calidad es igual a cierto tipo de productividad científica que se encuentra, en última instancia, determinado por el hecho de que las revistas en las que se publica figuren en base de datos SCIMAGO (Scopus), o del ISI Web of Knowledge y que es la expresión de un modelo del pensamiento colonizado que trasplanta los criterios de eficiencia y competencia empresarial al mundo académico, en el que calidad coincide con eficiencia administrativa (que miden organización e infraestructura aunque estos indicadores supuestamente se refieren al entorno de aprendizaje), cuyos criterios de medición administrativa se extienden desmedidamente y en el cual la pertinencia y competencia docente no tienen peso en un sub criterio denominado "academia", asumiendo que el $60 \%$ de profesores a tiempo completo es un porcentaje idóneo que garantiza calidad y sin explicar el por qué se ha tomado este porcentaje y un modelo en el cual el Estado desconoce otro tipo de universidad y que subvalora la relación de la universidad con la sociedad.

${ }^{23}$ El Modelo de Evaluación de las Universidades Ecuatorianas. Apuntes Críticos para el Debate. Manifiesto de más de 100 académicos ecuatorianos. Recuperado en agosto de 2016 de: https://universidadsociedadec.wordpress.com/manifiesto-modelode-evaluacion-ceaaces 
El Primer Pronunciamiento de los Académicos Ximena Díaz, Agustín Grijalva, Germán Rojas y Rocío Rueda ${ }^{24}$ (2014), bajo el título de «Académicos del Consejo de Educación Superior al País», señala:

«Los suscritos académicos... ante los actuales cuestionamientos al proceso de evaluación de las universidades y escuelas politécnicas, y en general a la relación de las instituciones de educación superior con el Gobierno Nacional, expresamos lo siguiente ante la opinión pública: 1) Reiteramos nuestra firme convicción de que el efectivo ejercicio de la autonomía responsable de las universidades y escuelas politécnicas, y su real participación en la política pública son una condición esencial para el mejoramiento académico...»

Reclaman un debate nacional serio, sin miedo a la crítica y que debe ser punto de reflexión con respecto a los modelos de la universidad que requiere el país, sin desconocer la importancia de las relaciones internacionales de las instituciones de educación superior.

Consideran que existen visiones gubernamentales, con respecto a las universidades, que pueden resultar «simplistas y reduccionistas», convirtiendo a éstas en «meros centros de producción de conocimiento funcional a necesidades empresariales o de mercado». Reconocen la prioridad que el gobierno nacional ha dado a la educación superior, pero reclaman unas políticas de Estado que garanticen continuidad, consenso y orientación suficientes para que la universidad pueda contribuir de manera trascendente a la transformación de las estructuras sociales, sobre todo en cuanto tiene que ver con la inequidad social.

El año 2016 ha sido un año de debate alrededor de la autonomía universitaria. Posiciones enfrentadas entre universidades y escuelas politécnicas y organismos de control y regulación de la educación superior. Inclusive, al debate se ha sumado el propio Presidente de la República acusando a las universidades particulares de enriquecimiento a costa de sus estudiantes, de que sus autoridades ganan cuantiosas cantidades de dinero y evaden impuestos, de que poseen cuentas bancarias en paraísos fiscales, de incumplimiento de las leyes, etc.

${ }^{24}$ Estos cuatro académicos han realizado tres pronunciamientos en total en forma de manifiestos públicos. Formaban parte, en el momento de sus pronunciamientos, del Consejo de Educación Superior -CES-. Su pronunciamiento es relevante por cuanto son miembros de uno de los organismos públicos que rigen el sistema de educación superior de Ecuador. Es el encargado de planificar, regular y coordinar el Sistema. Los académicos firmantes son parte de un grupo de seis académicos elegidos por concurso público de méritos y oposición. 
No se queda fuera de este debate María Paula Romo ${ }^{25}$ quien publica el 30 de enero de este año una columna en 4pelagatos titulada «La política del ultimátum ${ }^{26}$, en la que recuerda las palabras del presidente Correa el 29 de enero de 2016 con relación a la Universidad Andina Simón Bolívar: «Es universidad, si no cumple con la ley ecuatoriana se va del país, salgan a las calles quienes salgan. Prefiero perder mi cargo a permitir este insulto al pueblo ecuatoriano». Cita al Presidente y reflexiona sobre esta cita: «Esta semana el presidente Rafael Correa amenazó por décima cuarta ocasión (espero que la cuenta sea correcta, podrían ser más) con renunciar a su cargo...Él y su malsana idea de que tiene la verdad. Estos casos han sido sobre su ego, su palabra, su familia, sus creencias religiosas, su opinión personal sobre determinado caso (ya sea le Código Penal, el comportamiento de un embajador, o su estrategia para cooptar la Universidad Andina).

René Ramírez sale nuevamente a la palestra pública para desmentir afirmaciones sobre el interés que tendría el gobierno para poner candidato a Rector en la Universidad Andina Simón Bolívar ${ }^{27}$ «Al gobierno no le interesa poner ningún candidato» $\mathrm{y}$ «Hay un boicot expreso para que se de [sic] una salida, aparejado a un proceso electoral, detrás está el doctor Enrique Ayala Mora» 28: Recuerda que en enero de 2016 el Consejo de Educación Superior respaldó la decisión del Consejo Superior de la Universidad Andina Simón Bolívar de desconocer a César Montaño (que había sido elegido en elecciones universales y secretas) como rector por no cumplir con el requisito previsto en la Ley Orgánica de Educación Superior pues su título de doctorado es otorgado por la misma Universidad. «Respetamos la autonomía pero la Andina está acefálica [sic]»; lo dice, por su rector interino y por el plazo que el CES le diera a la Universidad hasta el 15

${ }^{25}$ Importante es anotar que esta joven abogada fue Asambleísta Constituyente (2008) y Asambleísta Nacional (2009-2013) por el movimiento político de izquierda Ruptura 25; movimiento que coalicionó con Alianza País. Muy cercana al Presidente de la República, hasta que en 2011 se separa del gobierno anunciando que el Presidente habría excedido sus funciones en el ejercicio del poder.

${ }^{26}$ Recuperado en enero de 2016 de: http://4pelagatos.com/2016/01/30/la-politicadel-ultimatum/

27 «En el mes de julio de 2015 se inició el proceso de elección de rector de la Sede Ecuador de la Universidad Andina Simón Bolívar, un organismo del Sistema Andino de Integración (SAI), de la Comunidad Andina (CAN), dedicado al posgrado y la investigación. Lo que debió ser un cambio de rector sin mayor trascendencia se convirtió en un espacio de disputa política y en un "laboratorio de la democracia», símbolo de la autonomía universitaria y de resistencia ante el poder.... Recuperado en agosto de 2016 de: http://www.uasb.edu.ec/web/autonomia-universitaria/cronologia

${ }^{28}$ Recuperado en agosto de 2016 de: http://www.elcomercio.com/actualidad/reneramirez-gobierno-candidato-rector-universidadandina.html 
de agosto de 2016, para fijar una fecha para realizar la consulta para elegirlo; y, hasta el 15 de octubre para tener autoridad designada.

Es justamente alrededor del tema de la Universidad Andina Simón Bolívar que continúa el debate al respecto de la autonomía universitaria y de la injerencia de instancias gubernamentales en la universidad ecuatoriana. En el diario La Hora se publica, en enero de 2016, un artículo que refiere la defensa de la Universidad la Andina de su autonomía ${ }^{29}$, un acto en defensa de ésta desarrollado en la misma Universidad con la asistencia del ex alcalde de Quito, el Gral. Paco Moncayo; el ex ministro de Defensa, José Gallardo; los ex asambleístas constituyentes Alberto Acosta, Martha Roldós y Diana Atamaint; la asambleísta nacional Lourdes Tibán; y, los dirigentes sindicales Pablo Serrano y Nelson Erazo ${ }^{30}$. Varios actores y una sola consigna: «Defendamos la autonomía universitaria».

Se encuentran también en el acto el rector saliente, el Dr. Enrique Ayala Mora; y, el entrante, el Dr. César Montaño. Los acompañan el Dr. Fernando Sempértegui, Rector de la Universidad Central y el Dr. Carlos Larreátegui, Rector de la Universidad de Las Américas. La nota reseña cuando Ayala Mora habla a los presentes y les recuerda que «no es un acto social, sino la radical expresión de un compromiso por la defensa de la autonomía y la dignidad de la educación superior del Ecuador». Le sigue Montaño: «hay sectores interesados en silenciar a esta institución, pero me comprometo a fortalecerla...esta universidad se ha caracterizado por ser sensible ante la realidad nacional y regional y nunca ha dejado de expresarse con libertad y espíritu crítico».

Hacia marzo de 2016, los cuatro académicos del CES (Díaz, Grijalva, Rojas y Rueda) publican un segundo manifiesto denominado "Consejeros Académicos del CES al País sobre las rentas públicas de la FLACSO y de la UASB-E». En éste y a propósito de las declaraciones del Presidente de la República en relación a la supresión de las rentas públicas que les corresponden a estas dos universidades, manifiestan que esta medida podría constituir una grave violación al articulado constitucional correspondiente a la asignación de rentas estatales a universidades y escuelas politécnicas («La Función Ejecutiva no podrá privar de sus rentas o asignaciones presupuestarias, o retar-

${ }^{29}$ Recuperado en julio de 2016 de: http://lahora.com.ec/index.php/noticias/ show/1101905648\#. V5ao3PnhDZ4

${ }^{30}$ Estos personajes son actores políticos reconocidos, militares en servicio pasivo, ex asambleístas constituyentes, analistas políticos, etc. Ellos han realizado análisis exhaustivos de la situación político-social del Ecuador en esta última década y han participado activamente en el debate social. 
dar las transferencias a ninguna institución del sistema...» Art. 355 de la Constitución de la República del Ecuador), y que les preocupa «sobremanera que esta posible decisión presidencial viole la autonomía financiera de estas universidades públicas, constituyéndose en un serio condicionante de la autonomía académica y en un grave y amenazante precedente para las demás universidades y escuelas politécnicas del país, cuyas rentas también están aseguradas por la Constitución y la Ley».

No desconocen que la autonomía universitaria deba ser responsable y que exista la debida sujeción por parte de universidades y escuelas politécnicas a los mecanismos de rendición de cuentas. Por ello, dicen respaldar «un mayor y estricto control del uso que de los recursos públicos hacen las universidades públicas y las particulares que reciben rentas o asignaciones del Estado». Manifiestan, además, que los ajustes y reformas que pudieran ser del caso si se comprobara un mal manejo de estos recursos, no pueden ser confundidos con la violación del derecho de percibir estas rentas que constitucionalmente están garantizadas: «En este sentido, resulta muy grave que, contrariando la política pública, el nivel de formación de maestría y de doctorado pueda verse restringido a sectores de altos ingresos, justamente en un momento crucial, en que por mandato de la LOES, el sistema de educación superior requiere urgentemente de docentes universitarios y politécnicos con esta formación académica y estas titulaciones».

Finalmente, recuerdan al país, que un cambio en el sistema de asignación de rentas estatales podría realizarse únicamente vía reformas de la Constitución y la Ley y que no podría operar sobre «un presupuesto aprobado y en ejecución», porque eso significaría «la interrupción inconstitucional e ilegal de las labores académicas de más de tres mil estudiantes que cursan posgrados en estas instituciones...». Así, enfatizando que es deber jurídico del Estado asegurar la continuación de estudios a sus ciudadanos, cierran su manifiesto.

Es todo este debate el que posiblemente provoca que el día 4 de marzo de $2016^{31}$, el Econ. Rafael Correa, ante las denuncias de la falta de entrega de recursos estatales ${ }^{32}$ a la Sociedad de Lucha contra el

${ }^{31}$ Recuperado en marzo de 2016 de: http://www.larepublica.ec/blog/politica/2016/03/04/correa-advierte-que-no-lo-amenacen-con-lo-de-solca-o-que-le-pasenlos-hospitales/

32 El asunto de la entrega de recursos estatales a universidades cofinanciadas y a entidades autónomas que por mandato constitucional o legal estuvieron percibiéndolas, se ha revisado desde el Gobierno de la Revolución Ciudadana por cuanto los ingresos del país cayeron estrepitosamente durante los años 2016 y 2017. Una nota de 
Cáncer -SOLCA- por un aproximado de 130 millones de dólares, advierta «que no lo amenacen mucho» con los problemas de SOLCA. El Presidente ha dicho que si no están contentos le pasen (al Estado) los hospitales de SOLCA para que sea éste quien atienda a los pacientes. Ha dicho:

«Basta ya de escándalos!». Y «Eso demuestra... que toditos dependían del gasto público... que son ellos los que no han sabido ahorrar ni manejar liquidez... una de las cosas que tiene que analizar el país son estas falsas autonomías: Autonomía universitaria, municipal, de las federaciones deportivas, del IESS, del ISSFA, de la Casa de la Cultura ¡Y de las fundaciones privadas autónomas! ¡Y toditas viven de la plata del Estado! ¡Esto no es verdadera autonomía! En otros países ustedes tienen grupos ciudadanos que hacen su fundación, ponen un hospital, ipero lo ponen de su plata, pues, o lo ponen con el auspicio del sector privado! Pero qué es esto, que ponen una fundación privada, y denme toda la plata del Estado. ¡Entonces debe ser una entidad pública! ¡Eso no es legítimo! ¡Si es plata del Estado, para un servicio público, debe ser público! ¡Si quieren dar un servicio público salud y ser privados, consigan sus fondos propios! Pero todo quieren del Estado... La primera autonomía es la autonomía financiera. Aquí todo el mundo quiere ser privado, con plata del Estado... No ven que en el gobierno no hay plata. Y quieren volver al pasado con una ley que les pre asigne recursos. ¡Señores, los tributos son del Estado, duela a quien le duela, y es el Estado el que debe administrarlos! ¡Para eso ganamos las elecciones! ¡Para eso, el pueblo ecuatoriano me dio cerca de cinco millones de votos!».

Estas declaraciones, salpicadas de vehemencia ${ }^{33}$, enardecen aún más el debate nacional con respecto a temas relacionados con entes históricamente autónomos y que por mandato constitucional y legal han percibido rentas estatales. Más aún, que por mandato constitucional y legal, no pueden ser privadas de sus rentas.

No cesa el debate sobre la autonomía universitaria y vuelve a aparecer en escena la Universidad Andina Simón Bolívar, cuando en un

prensa del diario El Comercio de Ecuador advierte que el día 11 de enero de 2016 el precio del petróleo llega a niveles no registrados desde diciembre de 2003: «El barril de crudo tipo West Texas Intermediate (WTI) cerró en el mercado de valores de Nueva York en USD 31,41 por barril...». Recuperado en marzo de 2017 de: http://www. elcomercio.com/actualidad/petroleo-cayo-precio-precio-2003.html

${ }^{33}$ En enero de 2008 Patricia Espinoza, en su espacio en red: Mi pluma Mi voz, publica un artículo de opinión intitulado: Correa ¿Un Presidente vehemente? Para esa fecha, Espinoza ya señalaba "Cada vez que tenemos la oportunidad de escuchar al Presidente de la República, sus expresiones transmiten confrontación, intolerancia, amenazas...No admite contradicción alguna venga de donde viniere...». Recuperado en marzo de 2017 de: http://www.miplumamivoz.com/2008/01/correa-un-presi. html 
comunicado publicado el 14 de julio de $2016^{34}$, Jaime Breilh Paz y Miño, Rector Encargado de esta Universidad, manifiesta que su Institución -por más de un año- ha soportado un intento de ser intervenida por medio de la eliminación de su autonomía y la privación de sus recursos. «El Gobierno y sus parlamentarios andinos aliados impidieron el ejercicio de su rector legítimamente designado». Denuncia que instituciones estatales acosan a la Universidad con «abrumadores trámites administrativos», pero que pese a ello, la Universidad Andina ha respondido "con firmeza y muestras de apertura para dialogar, pero la actitud intervencionista persiste a pesar de los acuerdos establecidos para salir de la crisis».

Pero el Presidente Correa tiene formado ya un criterio sobre las universidades particulares del país y así lo manifiesta en su enlace del 16 de julio de 2016 ${ }^{35}$ : «Más que indignación, me duele en el alma». Dice que ha descubierto que cinco universidades particulares están relacionadas con paraísos fiscales y que por ello se hace imprescindible una reforma a la Ley Orgánica de Educación Superior: "Gracias a las exoneraciones que les damos de impuestos y aranceles han logrado sacar más de 200 millones de dólares del país y cuando más se sacaron fue en el 2015, uno de los más difíciles del siglo, en cuanto a entorno económico». Advierte que de evidenciarse que los excedentes no se reinvierten en sí misma «se les acabará la fiesta». Señala que no habrá exoneraciones de impuestos ni aranceles y que se harán auditorías de cuyos resultados si deben pagase aranceles o impuestos retroactivamente, así lo tendrán que hacer.

Mientras el Presidente de la República hace estas declaraciones, la Facultad Latinoamericana de Ciencias Sociales -FLACSO- denuncia ${ }^{36}$ que el Estado le adeuda al menos ocho millones de dólares que corresponden a siete meses de transferencias impagas. Su representante manifiesta que la falta de recursos podría ocasionar que en octubre de 2016 no se abra el programa de maestría para el cual estaban admitidos 320 estudiantes ${ }^{37}$. Lamenta la situación de su Universidad,

\footnotetext{
${ }^{34}$ Recuperado en julio de 2016 de: http://www.uasb.edu.ec/contenido?comunicadode-la-universidad-andina-simon-bolivar-sede-ecuador

${ }^{35}$ Recuperado en julio de 2016 de: http://expreso.ec/actualidad/ecuador-rafael-correa-universidades-auditorias-aranceles-LJ496049

${ }^{36}$ Recuperado en julio de 2016 de: http://m.eluniverso.com/noticias/2016/07/14/ nota/5689932/flacso-universidad-andina-denuncian-estar-impagas-varios-meses

${ }^{37}$ Es necesario acotar que según el Reglamento de Sanciones del CES es falta muy grave «Suspender sin la aprobación del CES el desarrollo de las carreras y/o programas académicos que se encuentran en ejecución...» y «Suspender sin la aprobación del CES la apertura y ejecución de cohortes de carreras o programas vigentes». Las sanciones se podrán imponer a las instituciones de educación superior y/o a sus
} 
pues la FLACSO financia becas completas al 50\% de estudiantes de maestría y al 100\% de estudiantes de doctorado.

También el Rector de la Universidad Andina Simón Bolívar denuncia que le adeudan transferencias a su Universidad. Lo recoge la misma nota de prensa de la cual se desprende el párrafo anterior: «Una situación similar se vive en la Universidad Andina Simón Bolívar la cual también denunció que se le adeudan las transferencia estatales desde enero de 2016»

¿Nos arrodillamos o defendemos la autonomía universitaria? Se lo pregunta Ramiro Ávila Santamaría, abogado, experto en derechos humanos y ambientales y catedrático. Lo hace en su artículo publicado en julio de $2016^{38}$, en el que se pregunta, alrededor de un proyecto de reforma a la Ley Orgánica de Educación Superior que hiciera público la FLACSO «¿Por qué este gobierno tiene que actuar a espaldas y sin escuchar a quienes afectará sus decisiones? ¿Por qué tiene que tomar decisiones arbitrarias y adoptar también mecanismos arbitrarios para imponer su voluntad?».

El Presidente Correa, en la vorágine de las denuncias y las contra denuncias, debe desdecirse de una: la inclusión de la Universidad de Especialidades Espíritu Santo (UEES) entre las cinco universidades que tendrían capitales en paraísos fiscales. A través de su cuenta de Twitter ${ }^{39}$ y en cuanto se da cuenta del error cometido porque la misma UEES lo hace notar, se disculpa con la Universidad y con sus au-

máximas autoridades. Para las faltas muy graves, la sanción a las instituciones va desde una multa de entre 90 a 150 salarios básicos unificados (que en el año 2017 es de 375 dólares americanos), es decir de $\$ 33.750$ a $\$ 56.250$ ) cuando el infractor sea una Institución que cuente con menos de 500 estudiantes; y, de 300 a 500 salarios básicos unificados ( $\$ 112.500$ - \$187.500) si cuenta con más de 500 estudiantes, todo ello sin perjuicio del inicio del proceso de intervención si el CES considera que hay elementos para aquello. Para las máximas autoridades: amonestación escrita y suspensión de funciones por 60 días sin remuneración. (Artículos 13 y siguientes del Reglamento de Sanciones).

${ }^{38}$ Recuperado en julio de 2016 de: http://www.planv.com.ec/ideas/ideas/nos-arrodillamos-o-defendemos-la-autonomia-universitaria

${ }^{39}$ Yo no sé si es usual que un primer mandatario haga declaraciones importantes a través de una red social. Tal vez, por pertenecer a una generación en la cual no se conocían éstas, me sienta un poco predispuesta a que esto ocurra. Sin embargo, hay formalidades mínimas que cumplir y hay protocolos que no se pueden obviar. Una disculpa pública a una Universidad a la que días antes acusó de poseer dineros en paraísos fiscales, pero dineros productos de las exoneraciones tributarias con las cuales por mandato de Ley se benefician las universidades ecuatorianas, debería ocurrir de manera más solemne. Finalmente, esto resulta muy similar a la moraleja del hombre que fue conminado por su director espiritual a lanzar plumas de ave al viento y luego recogerlas. Lanzarlas resultó muy sencillo, recogerlas no. De hecho no se pudieron recoger todas, quedarían muchas. 
toridades: "se trata de una confusión -terrible- del SRI. Pedimos disculpas a las [sic] UESS y a sus autoridades». La suma anunciada en el enlace de los sábados es de 5.560.362,17.

Entre julio y agosto de 2016 se proponen reformas a la Ley Orgánica de Educación Superior, estableciendo que para el uso de recursos que no provengan del Estado las universidades particulares estarán sujetas a su propia normativa y a controles que, para el efecto, establezca el Consejo de Educación Superior ${ }^{40}$. Que existen "partes relacionadas» que no podrán ocupar cargos de representantes legales, directores, gerentes, administradores, ejecutivos principales o cargos de superior o similar jerarquía en las personas jurídicas creadas ${ }^{41}$, ni podrán ser titulares del capital social o de los fondos propios de esas personas jurídicas. Se establece que en el caso de que no se destinen los excedentes anuales a incrementar el patrimonio institucional, las universidades serán sancionadas según lo establece la misma reforma: multa económica de hasta un 10\% de los ingresos anuales de la institución, suspensión de la entrega de recursos públicos, descenso al inmediato inferior en la categoría institucional establecida por el CEAACES (¡!) y pérdida de las exoneraciones y beneficios tributarios hasta por un período de cinco años.

Además dispone que las instituciones de educación superior no puedan realizar contratos, convenios o transacciones con personas jurídicas domiciliadas, constituidas o ubicadas en paraísos fiscales o jurisdicciones de menor imposición; y, que no puedan realizar actos, contratos, convenciones u operaciones con partes relacionadas ${ }^{42}$. Si

${ }^{40}$ Constitucionalmente, la función del control le corresponde a la función de transparencia y control social, a través de su propio Consejo y de la Contraloría General del Estado.

${ }^{41}$ A partir del año 2010 y con la emisión de la Ley Orgánica de Educación Superior, las instituciones que realizaban actividades económicas, productivas o comerciales debían crear para el efecto, personas jurídicas distintas e independientes de la institución educativa. El mandato se encuentra contenido en el Art. 39 de la LOES, bajo el título «Prohibición de competencia desleal».

${ }^{42}$ Se refiere a promotores, rectores, vicerrectores, autoridades académicas, director financieros o cargos de igual o superior jerarquía, integrantes del órgano colegiado académico superior, cónyuges o los que mantengan unión de hecho o parientes dentro del cuarto grado de consanguinidad o segundo de afinidad de las autoridades antes señaladas; personas jurídicas en las cuales las personas antes señaladas sean representantes legales, fundadores, miembros asociados, directores, gerentes, administradores, ejecutivos principales o cargos de superior o similar jerarquía; y, las personas jurídicas, nacionales o extranjeras, en las que las autoridades antes indicadas sean titulares de la menos el $25 \%$ del capital social o de los fondos propios.

Esta reforma supone una mayor imposición normativa que, incluso, la que rige al sector público en el Ecuador. El Artículo 6 de la Ley Orgánica de Servicio Público, 
una universidad ignorara esta prohibición será sancionada con igual sanción que la antedicha para la no destinación de excedentes anuales en el patrimonio institucional.

Presentado que fuera el proyecto de reforma a la LOES en la Asamblea Nacional, la noticia se extiende con prontitud y es objeto de un nuevo debate. Carla Maldonado publica un artículo de opinión en el diario El Expreso ${ }^{43}$. En éste, Maldonado indica que el Gobierno «quiere empezar a fortalecer al CES para fiscalizar, investigar y sancionar a los infractores».

Nuevamente y por tercera ocasión los Consejeros Académicos del CES (Grijalva, Rueda, Rojas y Díaz) se dirigen al país con ocasión del proyecto de reforma de la Ley Orgánica de Educación superior presentada en la Asamblea Nacional por el Econ. René Ramírez. Los cuatro académicos, en este manifiesto, señalan que «Hacemos público nuestro voto en contra en el seno del Consejo de Educación Superior respecto a esta propuesta del oficialismo, debido a su alcance, al procedimiento y a partes de su contenido». Dicen coincidir con el principio general de que las universidades, institutos y conservatorios superiores, tanto particulares como públicos, no puedan tener fines de lucro y que la educación debe responder al interés social y público y no a los intereses individuales y corporativos.

Sin embargo, consideran que la propuesta del oficialismo se reduce a un tema limitado, y llaman la atención al país sobre el hecho de que en seis años de aplicación de la LOES se ha evidenciado la necesidad de reformar ésta pero al tenor de otras temáticas: integración del CES y CEAACES y de los consejos universitarios y politécnicos, requisitos para el ingreso y promoción en el escalafón docente, relación del CES y CEAACES con el Ejecutivo, rol de SENESCYT, políticas de evaluación de las instituciones de educación superior y de sus carreras, sistema de ingreso a las instituciones de educación superior, cursos de nivelación, manejo del sistema de información y otros.

establece «Se prohíbe a toda autoridad nominadora, designar, nombrar, posesionar y/o contratar en la misma entidad, institución, organismo o persona jurídica, de las señalas en el artículo 3 de esta Ley, a sus parientes comprendidos hasta el cuarto grado de consanguinidad y segundo de afinidad, a su cónyuge o con quien mantenga unión de hecho». Nótese que establece la prohibición en cuanto a la autoridad nominadora. La norma reformatoria a la Ley de Educación Superior, entonces, tiene un alcance mayor, por tanto se refiere a las autoridades máximas de una universidad particular y no solamente a la nominadora.

${ }^{43}$ Recuperado en julio de 2016 de: http://expreso.ec/actualidad/universidades-privadas-control-rigidos-YX505221 
Denuncian que el procedimiento para aprobar la propuesta, aprobada por la «mayoría oficialista del CES», duró apenas dos días, considerando que éste es un tiempo insuficiente para el debate de un tema tan complejo. Que no hubo socialización con directivos y miembros de la comunidad universitaria particular involucrada. Señalan que, si bien no es aceptable que algunas universidades particulares paguen a sus autoridades «latisueldos» o que se haya uso inadecuado de los recursos estatales; tampoco es aceptable que «para asegurar la fiscalización, responsabilidad social, rendición de cuentas y participación en la planificación nacional...se limite o elimine inconstitucionalmente su autonomía académica, administrativa y financiera, garantizada en la misma norma constitucional».

Consideran que el posible lucro de las universidades y la detección de ello, revela en realidad, deficiencias institucionales de organismos de control tales como Servicio de Rentas Internas, Superintendencia de Compañías, Superintendencia del Poder de Mercado, SENESCYT y hasta el mismo CES. Deben activarse, a su criterio, los marcos institucionales y normativos para un control eficiente. Enfatizan que cualquier reforma a la Ley Orgánica de Educación Superior debe encaminarse a fortalecer la autonomía universitaria (financiera, administrativa, orgánica) para propiciar que las universidades tengan mayores controles internos y que estos controles estén plasmados en sus propios estatutos y normativa.

La agencia de noticias Andes publica el 26 de julio de 2016 una nota de prensa en la cual se recogen las impresiones de René Ramí$r^{4} z^{44}$ con respecto a la presentación del proyecto de reformas a la LOES entregado a la Asamblea Nacional. En la nota se dice que el Presidente del Consejo de Educación Superior ha indicado que el proyecto «busca garantizar la democratización de la educación y evitar que las universidades "tengan dueños" ya que estas instituciones deben ser de toda la comunidad académica...se busca desvincular cualquier tipo de propiedad que se quiera tener sobre las universidades particulares».

Las declaraciones de Ramírez enfatizan en el hecho de que la discusión surge a partir de la aparición de los denominados «Panama Papers ${ }^{45}$, que entre otros, revelaron la vinculación de «ciertas univer-

${ }^{44}$ Recuperado en agosto de 2016 de: http://www.andes.info.ec/es/noticias/reformas-ley-organica-educacion-superior-llegaran-este-martes-asamblea-ecuador.html

45 «El Consorcio Internacional de Periodistas Investigativos (ICIJ) cumplió ayer con poner a la disposición de la opinión pública la base de datos de más de 200 mil empresas de pantalla, trusts y fundaciones con sede en 21 paraísos fiscales "desde Hong Kong hasta Nevada, e en Estados Unidos (EE. UU.)». Nota de prensa recupera- 
sidades particulares con paraísos fiscales». Una investigación del SRI demostraría que estas universidades no están cumpliendo con el artículo de la LOES que dispone que las instituciones de educación superior no tendrán fines de lucro.

Ramírez, en las mismas declaraciones, ha señalado que «Las universidades particulares han movido 2.800 millones de dólares, que nos son cantidades menores. De acuerdo a las informaciones del SRI existen excedentes de 200 millones de dólares que no son reinvertidos en las instituciones». Sus declaraciones incluyen también el tema de la contratación con empresas vinculadas: "Las universidades sacan alrededor de 197 millones de dólares anuales del país hacia paraísos fiscales... lo que constituye una práctica deshonesta... se firman contratos entre las universidades y empresas vinculadas a sus autoridades para "redondear" los sueldos...» Con las reformas se busca dar potestad sancionadora al CES; y, al SRI, para pedirle cuentas a las universidades particulares». Ha destacado que los aranceles en Ecuador son, en promedio, de $\$ 5.600$ (cinco mil seiscientos dólares americanos) y que las prácticas que han ocasionado el proyecto de reforma a la LOES hacen que se eleven los costos y que éstos, finalmente, son pagados por el estudiante o por el padre de familia: "... estamos proponiendo que en el caos de encontrar estas prácticas el CES pueda tomar la decisión de bajar los aranceles a estas universidades».

El debate, como se puede ver en estas páginas, es dinámico. Entre pronunciamientos de uno y otro sector, ha transcurrido una década. El sector oficialista, con el mismo Presidente de la República a la cabeza, ha sostenido que la universidad ecuatoriana ha vivido -conjuntamente con todo el país- una larga noche neoliberal y que hacía falta una intervención estatal para lograr una democratización de la educación superior; y, el sector universitario, representado por rectores, académicos e intelectuales, que ha sostenido la necesidad de que el Estado regule el sector de la educación superior, pero que el híper control atenta contra el principio constitucional de autonomía universitaria.

da en agosto de 2016 de: http://www.eltelegrafo.com.ec/noticias/economia/8/en-lospanama-papers-pasan-de-3-a-928-los-ecuatorianos-vinculados-con-firmas-offshore que difunde que serían 1852 empresas offshore vinculadas a Ecuador, 928 directivos, 325 intermediarios y 617 direcciones registradas. La misma nota de prensa destaca que por parte del Sistema de Rentas Internas de Ecuador se han identificado 589 empresas offshore que tienen alguna vinculación con el estudio jurídico panameño Mossack Fonseca y que han sido creadas para clientes ecuatorianos. 


\section{CONCLUSIONES}

La universidad contemporánea, ciertamente, sufre grandes cambios. La universidad ecuatoriana no es una excepción y mucho menos en lo que concierne a esta última década (2006-2016), cuando el sector de la educación superior ha sido objeto de cambios trascendentes. Asuntos como la globalización y la producción de norma nacional con respecto a este campo, han variado el escenario de tal manera, que resulta difícil reconocer en la universidad ecuatoriana actual lo que fuera hace 10 años.

No me refiero ahora al hecho de la bondad o la perversidad de estos cambios, porque resulta complejo señalarlo. Me refiero a que los cambios son evidentes y creo que esto es innegable. La cuestión está en si estos cambios han logrado su cometido, cual es el de una universidad de calidad, pertinente y acorde a las necesidades sociales.

Cambiar un orden es difícil tarea y no pocas veces, además, beligerante. Más que un debate, se ha generado una gran discusión nacional. El cambio ha significado muchísima norma -producida y reformada a impresionante velocidad- que vuelve compleja la gestión universitaria.

Múltiples voces se alzaron entre los años 2009 y 2010 con respecto a lo que sería la Ley Orgánica de Educación Superior. Estas voces en su mayor parte traían consigo la advertencia de que se estaría denostando la autonomía universitaria. No sólo son los dichos, también son los hechos. Los estudiantes, los docentes, las autoridades universitarias se vuelcan a las calles a reclamar la capacidad de las universidades de autogobernarse. El sector estatal, por su parte, clama por una reforma que considera necesaria y trascendental, que permitiría la democratización de la educación superior y terminaría con un largo período en el cual se habría dado paso a la privatización de la educación superior y al corporativismo de ésta.

A partir de estos debates y sin que de ellos se haya podido extraer algún tipo de acuerdo, más allá de algunas socializaciones que se llevan a cabo con ciertos sectores, se expide la Ley Orgánica de Educación Superior en octubre de 2010 y con ello se conmociona el tablero de lo que había sido hasta ese momento la educación superior en Ecuador.

Uno de los manifiestos públicos más relevantes es el suscrito por más de 100 académicos ecuatorianos de distintas universidades y escuelas politécnicas ecuatorianas y que se publica en el año 2014. Este documento contiene la preocupación de los académicos por el proce- 
so de evaluación del CEAACES y un modelo vertical que no toma en cuenta la realidad ecuatoriana de la educación superior. Pero abonan aún más al debate público los tres manifiestos que realizan cuatro académicos del Consejo de Educación Superior; en estos manifiestos se puede encontrar, como denominador común, la preocupación de un sistema de educación superior imperativo que desconozca la autonomía universitaria en la universidad ecuatoriana.

Son muchos los que se han pronunciado en el sentido de que se estaría coartando la autonomía académica, financiera y administrativa de las universidades y escuelas politécnicas, públicas y particulares, del Ecuador. Los pronunciamientos oficiales, los de la Revolución Ciudadana, concluyen que no hay coacción a la autonomía universitaria, que se trata de normar sobre lo que no se normó y de acabar con un sistema perverso que hipermercantilizó a la universidad en los años ochenta y noventa del siglo pasado.

\section{BIBLIOGRAFÍA}

Aguirre, Manuel Agustín. 1973. La Segunda Reforma Universitaria. Selección de Documentos. Universidad Central del Ecuador.

Arcos CABrera, Carlos. 2010. La autonomía como argumento político. Transformar la Universidad para transformar la sociedad. Secretaría Nacional de Planificación y Desarrollo. Quito, Ecuador.

Corrales, Manuel. 2012. «Autonomía Universitaria». Pontificia Universidad Católica del Ecuador. Rectorado. Quito, Ecuador.

Díaz, X.; Grijalba, A.; Rojas, G.; Rueda, R. 2014. "Académicos del Consejo de Educación Superior al País». Quito, Ecuador

LANDA Goyogana, Josu. 2000. «Autonomía Universitaria y Globalización». Estado, Universidad y Sociedad: entre la globalización y la democratización. Tomo I. Centro de investigaciones Interdisciplinarias en Ciencias y Humanidades de la Universidad Autónoma de México. México, D. F.

LARREA, Ana María. "Autonomía universitaria y sociedad de mercado (Coyuntura)». En: La Tendencia. Revista de Análisis Político. Nuevo momento: acuerdo nacional por el cambio. Quito: FES-ILDIS, (no. 10, febrero-marzo 2010): pp. 61-66. ISSN: 13902571

Manifiesto Liminar de Córdoba -21 de junio de 1918- La Juventud Argentina de Córdoba a los Hombres Libres de Sud América. 
Mayor Zaragoza, Federico. (2011). Delito de Silencio. Ha llegado el momento. Es tiempo de acción. Barcelona: Editorial Comanegra.

OrdoriKa, Imanol. 2006. La Disputa por el Campus. Poder, Política y Autonomía en la UNAM. Universidad Nacional Autónoma de México. México D. F.

Valencia Carmona, Salvador. 2003. Derecho, autonomía y educación superior. Universidad Nacional Autónoma de México. México D. F.

VILlAVICENCIO, A. 2013. «¿Hacia dónde va el proyecto universitario de la revolución ciudadana?». Recuperado en julio de 2016 de: http:// repositorio.uasb.edu.ec/bitstream/10644/3235/1/Villavicencio,\%20 A-CON-001-Hacia\%20donde.pdf

WOLDENBERG, José. Enero-abril 2008. «Autonomía Universitaria: Esbozo histórico y significado». Revista Universidades. Año LVIII. No. 36. México, D. F. 